\title{
Fecal Calprotectin as a Predictor of COVID-19 Severity
}

\author{
Mohammed Hussien Ahmed ${ }^{1}$ Hebat Allah Abdel Maksoud Ahmed $^{2}$ Nahla Abd el-Aziz Nosair ${ }^{3}$ \\ Asmaa Mbarak Hassan ${ }^{3}$ Dalia ElSayed Sherief ${ }^{3}$ Aya Mohammed Mahros ${ }^{1 \odot}$ \\ ${ }^{1}$ Department of Hepatology, Gastroenterology and Infectious \\ Diseases, Faculty of Medicine, Kafrelsheikh University, Kafrelsheikh, \\ Egypt \\ 2 Department of Community Medicine, Faculty of Medicine, \\ Kafrelsheikh University, Kafrelsheikh, Egypt \\ ${ }^{3}$ Department of Clinical Pathology, Faculty of Medicine, Kafrelsheikh \\ Address for correspondence Mohammed Hussien Ahmed, MD, \\ Department of Hepatology, Gastroenterology and Infectious Disease, \\ Faculty of Medicine, Kafrelsheikh University, El Wakeal area, \\ Kafrelsheikh Governorate, 33511, Kafrelsheikh, Egypt \\ (e-mail: dr.mm63@yahoo.com; \\ mohammed_hessien@med.kfs.edu.eg).
} University, Kafrelsheikh, Egypt

J Coloproctol 2021;41(4):361-366.

\begin{abstract}
Keywords

- coronavirus disease 2019

- severe acute respiratory syndrome coronavirus 2

- predictors in reflection of the severity in Covid 19 patients

Coronavirus disease 2019 (COVID-19) is highly transmittable through contact with respiratory droplets. The virus is also shed in fecal matter. Some patients may present with effects in more than one system; however, there are no defined biomarkers that can accurately predict the course or progression of the disease. The present study aimed to estimate the severity of the disease, to correlate the severity of the disease with biochemical predictors, to identify valuable biomarkers indicative of gastrointestinal disease, and to determine the cutoff values. A cross-sectional study was conducted on COVID-19 patients admitted to the Kafrelsheikh University Hospital (isolation unit) between July 10, 2020, and October 30, 2020. The diagnosis of COVID19 was confirmed via reverse transcription-polymerase chain reaction (RT-PCR), which was employed for the detection of the viral RNA. We conclude that lymphopenia, elevated C-reactive protein (CRP) level, and liver enzymes were among the most important laboratory findings in COVID-19 patients. Statistically significant differences in platelet count, neutrophil count, D-dimer level, and fecal calprotectin levels were observed among patients presenting with chest symptoms only and patients with both chest and gastrointestinal symptoms $(p=0.004 ;<0.001 ; 0.010 ; 0.003$; and $<0.001$, respectively). C-reactive protein, D-dimer, and fecal calprotectin levels positively correlated with disease severity. The cutoff value for fecal calprotectin that can predict gastrointestinal involvement in COVID-19 was 165.0 , with a sensitivity of $88.1 \%$ and a specificity of $76.5 \%$.
\end{abstract}

\section{Introduction}

In Wuhan, Hubei Province, China, in December 2019, a COVID19 outbreak caused by the 2019 novel severe acute respiratory

received January 30, 2021 accepted after revision June 15, 2021
DOI https://doi.org/ $10.1055 / \mathrm{s}-0041-1736646$. ISSN 2237-9363. syndrome coronavirus 2 (SARS-CoV-2) occurred. Coronaviruses are a large family of viruses. It has been found that people are commonly infected with 4 human coronaviruses: 229E, NL63, OC43, and HKU1. Middle East respiratory syndrome
(C) 2021. Sociedade Brasileira de Coloproctologia. All rights reserved.

This is an open access article published by Thieme under the terms of the Creative Commons Attribution-NonDerivative-NonCommercial-License, permitting copying and reproduction so long as the original work is given appropriate credit. Contents may not be used for commercial purposes, or adapted, remixed, transformed or built upon. (https://creativecommons.org/ licenses/by-nc-nd/4.0/)

Thieme Revinter Publicações Ltda., Rua do Matoso 170, Rio de Janeiro, RJ, CEP 20270-135, Brazil 
(MERS), severe acute respiratory syndrome (SARS), and the most recently discovered coronavirus disease 2019 (COVID-19) cause infectious disease, including severe acute respiratory syndrome coronavirus 2 (SARS-CoV-2). ${ }^{1}$ COVID-19 is highly transmittable, mainly through contact with respiratory droplets. In addition, the virus can spread when small droplets released from the upper respiratory tract secretions of an infected individual land on surfaces and then individuals touch these surfaces and then, subsequently, touch their eyes, nose, or mouth. ${ }^{2}$ The virus is also shed for an extended period in fecal matter.

The typical clinical manifestations of COVID-19 include fever, cough, and pneumonia, which can eventually lead to more severe respiratory failure and acute respiratory distress syndrome (ARDS). In addition, gastrointestinal manifestations include nausea and vomiting, abdominal pain, anorexia, and diarrhea in some cases, which can be explained by an abundant expression of Angiotensin-Converting Enzyme 2 (ACE2) in the epithelial cells of the gastrointestinal (GI) tract and the tissue distribution of ACE2 in the human body may also suggest potential infection routes and targets of SARSCoV-2. ${ }^{3}$ In $\sim 50 \%$ of patients, COVID-19 RNA was detected in feces. The virus may actively infect cells of the GI tract, replicating itself in the epithelium of the small and large intestines, which causes an excessive immunological reaction. The immunological reaction results in the production of numerous cytokines, including interleukin 6 (IL-6), tumor necrosis factor $\alpha$ (TNF- $\alpha$ ), and interferon $\alpha$ (INF- $\alpha)$, by activated leukocytes and neutrophils. Acute liver injury in healthy individuals has been reported in a few studies. Mortality from COVID-19 was particularly high among patients with more advanced cirrhosis and those with alcohol-related liver disease. ${ }^{4-6}$

Calprotectin is a calcium- and zinc-binding protein of the S-100 family of proteins. It is widely considered as a useful tool for identifying damage to the intestinal mucosa. In fact, calprotectin is useful for the diagnosis of any organic intestinal disease that causes inflammation of the intestinal wall. The expression of calprotectin is mainly restricted to the intracellular compartment of neutrophils. ${ }^{7}$

D-dimer is a degradation product of cross-linked fibrin resulting from plasmin cleavage. The role of $\mathrm{D}$-dimer in COVID-19 patients has not been fully investigated. ${ }^{8}$

To the best of our knowledge, no Egyptian studies that address the indicators of COVID-19 and the predictors of severity exist. The present study aimed to estimate the severity of the disease in patients admitted to the Kafrelsheikh University Hospital (isolation unit), to correlate the severity of the disease with biochemical predictors, to identify valuable biomarkers for gastrointestinal disease, and to determine the cutoff values.

\section{Methods}

\section{Study Population}

A cross-sectional study was conducted on COVID-19 patients admitted to the Kafrelsheikh University Hospital (isolation unit), a tertiary hospital, between July 10, 2020, and October 30, 2020.
The diagnosis of COVID-19 was confirmed via reverse transcription-polymerase chain reaction (RT-PCR), which was used to detect the viral RNA (cobas 6800 system; Roche, Basel, Switzerland), according to the definitions by the World Health Organization (WHO) and the Egyptian Ministry of Health and Population $(\mathrm{MOH}) .^{8}$ The inclusion criteria included hospitalization due to COVID-19 (confirmed via RT-PCR test). We excluded every patient with a history of autoimmune disease, inflammatory bowel disease, or confirmed deep vein thrombosis or pulmonary embolism.

\section{Laboratory and Imaging Methods}

Complete blood count, coagulation profile, renal and liver function, D-dimer level, ferritin level, C-reactive protein (CRP) level, and fecal calprotectin level were determined routinely upon admission. The D-dimer level was measured via an immunoturbidimetric assay with a reference range of $<250 \mathrm{mg} / \mathrm{L}$ (CS-5100; Sysmex Corporation, Kobe, Japan). The seventh edition of the Chinese Novel Coronavirus Pneumonia Diagnosis and Treatment Plan incorporates computed tomography (CT) imaging into the criteria that clinically define COVID-19. ${ }^{9}$

\section{Classification of Participants}

The target group was subdivided into two groups according to the presentation of the disease. Group A consisted of patients who were positive for COVID-19 according to the PCR test and presented with chest symptoms only. Group B consisted of patients that were positive for COVID-19 according to the PCR test and presented with both chest and GI symptoms.

\section{Severity Assessment}

The clinical severity of the COVID-19 symptoms was classified into mild/moderate (-Fig. 1a) or severe/critically ill (-Fig. 1b), according to the Novel Coronavirus Pneumonia Diagnosis and Treatment Guideline developed by the National Health Commission of the People's Republic of China. ${ }^{9}$ Radiologically, the area of the affected lungs consistent with viral pneumonia was determined from each the first chest CT of each patient after admission.

\section{Sampling}

The selected sample for our study included COVID-19 patients admitted to the isolation unit in the Kafrelsheikh University Hospital between July 10, 2020, and October 30, 2020.

\section{Statistical Analyses}

Data sorting and analysis were performed using IBM SPSS Statistics for Windows, version 21 (IBM Corp., Armonk, NY, USA). The qualitative variables were described using numbers and percentages. The chi-squared test was employed for the analysis (the Fisher exact test was used as an alternative to the chi-squared test if there were many small expected values). Numerical variables were expressed as medians (interquartile range [IQR]). The Mann-Whitney U-test (for non-normally distributed data) was employed for the 


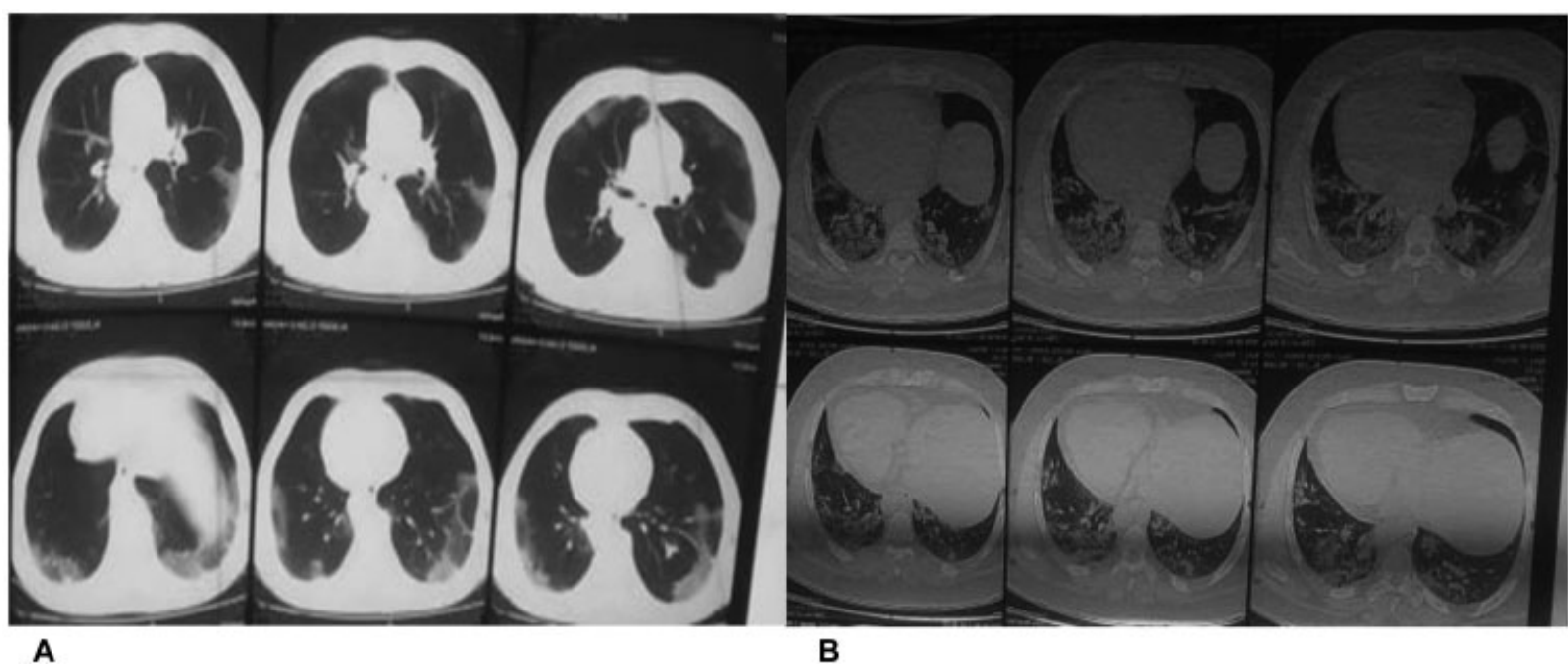

Fig. 1 (A) female patient, 40 years old, with mild covid 19 infection (B) male patient, 60 years old, with severe symptoms.

comparisons between the groups. The Spearman correlation coefficient was used for the correlation analysis between ordinal and non-normally distributed variables. Receiver operating characteristic (ROC) curves were used to determine the optimum cutoff points of parameters in severe patients. A p-value $<0.05$ was adopted as the level of significance.

\section{Ethics and Consents}

Written informed consent was obtained from all adult participants or from the parents or legal guardians of patients $<18$ years old. The study protocol was approved by the ethics committee of the Faculty of Medicine, Kafrelsheikh University. The study was conducted in accordance with the provisions of the Declaration of Helsinki, Good Clinical Practice, and applicable regulatory requirements.

\section{Results}

A total of 211 patients diagnosed with COVID-19 were selected to fulfill the inclusion criteria and were enrolled in the study. - Table 1 presents the demographics and laboratory information of the enrolled patients. The mean age of the patients was 40 years old, with no statistically significant difference between the groups $(p=0.390)$. The study participants consisted of 103 (48.8\%) males and 108 (51.2\%) females, with no significant difference between the groups. Platelet count, neutrophil count, D-dimer level, and serum and fecal calprotectin levels were significantly different between the groups ( $p=0.004 ;<0.001 ; 0.010 ; 0.003$; and $<0.001$, respectively). Disease severity was higher in Group B patients (with both GI and chest symptoms) compared with Group A patients (with chest manifestations only) ( $p<0.001)$. No other significant differences in laboratory parameters between the groups were observed.

- Table 2 presents the correlation between laboratory tests and disease severity in Group A. The CRP levels were significantly different between the disease severity groups $(p=0.038)$. No other significant differences were observed. - Table 3 presents the correlation between laboratory tests and disease severity in Group B. D-dimer and fecal calprotectin levels were significantly different between the disease severity groups ( $p=0.031$ and $p>0.001$, respectively).

As presented in - Tables $\mathbf{4}$ and $\mathbf{5}$, Spearman correlation analysis was conducted to determine the relationship between disease severity, CRP, D-dimer and fecal calprotectin levels in COVID-19 patients in group B (with both GI and chest symptoms). Disease severity was moderately correlated with fecal calprotectin, and such a correlation was statistically significant $(r=0.672 ; n=59 ; p<0.001)$. To better detect severe illness in COVID-19 patients in Group B (with both GI and chest symptoms), the ROC curve of fecal calprotectin was generated, as presented in - Fig. $\mathbf{2}($ AUC $=0.921$; 95\% confidence interval [CI]: 0.855-0.987; $p<0.001$ ). The best cutoff point to identify patients with GI symptoms using fecal calprotectin was 165.0 , which results in a sensitivity of $88.1 \%$ and a specificity of $76.5 \%$.

\section{Discussion}

The COVID-19 pandemic represents a catastrophic event worldwide. In patients, more than one system may be affected by COVID-19. In the present study, the relationship between disease severity and clinical and biochemical indicators was comprehensively analyzed.

The median age of the enrolled patients with COVID-19 was 40 years old, with no statistically significant differences in age or gender between the groups. The average age was slightly lower than the average age of COVID-19 patients reported by Huang et al. (median, 58 years; IQR, 39-67; range, 14-84 years old) ${ }^{10}$ In our study, the most frequent laboratory abnormalities in both groups were lymphopenia, elevated CRP level, liver enzymes, platelet and neutrophil counts, D-dimer, and serum and fecal calprotectin levels. These results agreed with the published studies by Liu et al. and Wan et al..$^{11,12}$

Hoffmann, Zhang, and colleagues indicated that SARSCoV-2 binds to cells in the GI tract (for example, small and large intestinal epithelial cells), likely via specific receptors, 
Table 1 Demographics and baseline characteristics of COVID-19 patients

\begin{tabular}{|c|c|c|c|c|c|}
\hline & Group A $(n=152)$ & Group B $(n=59)$ & Total $(n=211)$ & Test & p-value \\
\hline Male gender & $70(64.1 \%)$ & $33(55.9 \%)$ & $103(48.8 \%)$ & \multirow[t]{2}{*}{$\mathrm{U}$} & \multirow[t]{2}{*}{0.198} \\
\hline Female & $82(53.9 \%)$ & $26(44.1 \%)$ & $108(51.2 \%)$ & & \\
\hline Age & $40.0(40.0-50.0)$ & $40.0(38.0-50.0)$ & $40.0(40.0-50.0)$ & $\mathrm{U}$ & 0.390 \\
\hline Hemoglobin $(g / l)$ & $13.5(10.5-15.2)$ & $13.4(11.9-14.4)$ & $13.6(11.3-14.9)$ & U & 0.960 \\
\hline WBC count $\left(\times 10^{9} / \mathrm{L}\right)$ & $10.5(7.8-15.4)$ & $13.4(8.5-16.5)$ & $10.8(8.1-15.8)$ & $\mathrm{U}$ & 0.221 \\
\hline Platelet count $\left(\times 10^{9} / \mathrm{L}\right)$ & $197.3(136.3-247.5)$ & $140.7(118.5-213.0)$ & $187.9(128.8-228.8)$ & $\mathrm{U}$ & $0.004^{*}$ \\
\hline Basophil count $\left(\times 10^{9} / \mathrm{L}\right)$ & $0.3(0.3-0.5)$ & $0.4(0.3-0.5)$ & $0.3(0.3-0.5)$ & $\mathrm{U}$ & 0.728 \\
\hline Eosinophil count $\left(\times 10^{9} / \mathrm{L}\right)$ & $0.2(0.1-0.6)$ & $0.2(0.1-0.4)$ & $0.2(0.1-0.6)$ & $\mathrm{U}$ & 0.198 \\
\hline Neutrophil count $\left(\times 10^{9} / \mathrm{L}\right)$ & $78.2(54.6-86.2)$ & $86.2(74.9-90.2)$ & $79.7(62.0-88.0)$ & $\mathrm{U}$ & $0.000^{*}$ \\
\hline Lymphocyte count $\left(\times 10^{9} / \mathrm{L}\right)$ & $11.6(7.2-18.2)$ & $8.2(6.1-16.2)$ & $11.1(6.7-18.1)$ & $\mathrm{U}$ & 0.079 \\
\hline Monocyte count $\left(\times 10^{9} / \mathrm{L}\right)$ & $8.1(4.5-14.0)$ & $6.5(4.1-11.2)$ & $7.9(4.5-13.0)$ & $\mathrm{U}$ & 0.058 \\
\hline C-reactive protein (mg/l) & $50.0(16.0-96.4)$ & $80.0(24.0-112.0)$ & $52.8(16.0-109.0)$ & $\mathrm{U}$ & 0.067 \\
\hline D-dimer (ng/ml) & $100.0(20.0-221.0)$ & $221(20.0-1120.0)$ & $100.0(20.0-400.0)$ & $\mathrm{U}$ & $0.010^{*}$ \\
\hline AST (U/L) & $59.8(25.2-120.0)$ & $62.6(28.9-130.8)$ & $62.6(28.0-120.0)$ & $\mathrm{U}$ & 0.539 \\
\hline $\operatorname{ALT}(U / L)$ & $51.7(32.0-120.3)$ & $81.0(32.0-140.4)$ & $57.6(32.0-132.0)$ & $\mathrm{U}$ & 0.083 \\
\hline Bilirubin $(\mu \mathrm{mol} / \mathrm{L})$ & $0.7(0.6-0.8)$ & $0.9(0.5-1.0)$ & $0.7(0.6-0.9)$ & $U$ & $0.003^{*}$ \\
\hline Albumin $(\mathrm{g} / \mathrm{dl})$ & $3.6(3.1-3.9)$ & $3.7(3.3-3.9)$ & $3.7(3.2-3.9)$ & $U$ & 0.326 \\
\hline Ferritin (ng/ml) & $120.0(50.0-300.0)$ & $180.0(60.0-300.0)$ & $120.0(50.0-300.0)$ & $\mathrm{U}$ & 0.269 \\
\hline Fecal calprotectin (mic/g) & $40.0(20.0-70.0)$ & $200.0(150.0-250.0)$ & $60.0(30.0-150.0)$ & $\mathrm{U}$ & $0.000^{*}$ \\
\hline \multicolumn{6}{|l|}{ Disease severity } \\
\hline Mild/Moderate & $150.0(98.7 \%)$ & $17.0(28.8 \%)$ & $167.0(79.1 \%)$ & 125.7 & $0.000^{*}$ \\
\hline Severe & $2.0(1.3 \%)$ & $42.0(71.2 \%)$ & 44.0 (20.9\%) & & \\
\hline
\end{tabular}

${ }^{*} \mathrm{p}<0.05$

such as ACE2 and the transmembrane serine protease 2 . $^{13,14}$ In our study, we found that fecal calprotectin levels increased in patients with GI symptoms and was positively correlated with disease severity. The fecal calprotectin cutoff value for predicting gastrointestinal symptoms was 165.0 , with a sensitivity of $88.1 \%$ and a specificity of $76.5 \% .^{13,14}$

Most patients in our study had mild to moderately severe symptoms. Only $20.9 \%$ of the patients presented with severe or critical disease. The biomarkers that positively correlated with disease severity were CRP in Group A (chest symptoms only) and D-dimer and fecal calprotectin in Group B (chest and GI symptoms). Querol-Ribelles et al. found a correlation between elevated levels of D-dimer and severe COVID-19 disease and a higher mortality rate of community-acquired pneumonia. Chen et al. also reported that the level of plasma CRP positively correlated with the severity of COVID-19 pneumonia. $^{15,16}$

The present study has several limitations. First, it was conducted in a single center and on Egyptian patients only; therefore, we recommended further studies to confirm these findings. Second, we did not examine the serial values of the potential predictors while assessing COVID-19 patients. However, we believe that several points in the methodology overcome the limitations of previous studies. First, all patients in the study were examined and scored by the same experienced physician. Second, we classified the patients according to the National Health Commission of the People's Republic of China. Third, this was not a retrospective study; the investigation was conducted in a crosssectional fashion and sometimes prospectively. Consequently, we collected all the potentially important clinical and laboratory parameters.

\section{Conclusions}

Lymphopenia, elevated CRP level, and liver enzymes are among the most important laboratory findings in COVID-19 patients. Platelet and neutrophil counts, D-dimer level, and fecal calprotectin level were significantly different between patients presenting only with chest symptoms and patients presenting with both chest and GI symptoms $(p=0.004 ;<0.001 ; 0.010 ; 0.003$; and $<0.001$, respectively). C-reactive protein, D-dimer, and fecal calprotectin levels positively correlated with disease severity. The fecal calprotectin cutoff value for the prediction of gastrointestinal symptoms in COVID-19 patients is 165.0 , with a sensitivity of $88.1 \%$ and a specificity of $76.5 \%$. 
Predictors of the Severity in COVID-19 Patients Ahmed et al. 365

Table 2 Correlation between disease severity and clinical and biochemical characteristics in COVID-19 patients presenting with chest symptoms only

\begin{tabular}{|c|c|c|c|c|}
\hline & Mild/Moderate $(n=150)$ & Severe/Critical $(n=2)$ & Test & $p$-value \\
\hline Male gender & $70(46.7 \%)$ & $0(0.0 \%)$ & \multirow[t]{2}{*}{$\mathrm{FE}$} & \multirow[t]{2}{*}{0.500} \\
\hline Female & $80(53.3 \%)$ & $2(100.0 \%)$ & & \\
\hline Age & $40(40-50)$ & $40.0(40.0-40.0)$ & $\mathrm{U}$ & 0.639 \\
\hline Hemoglobin $(\mathrm{g} / \mathrm{l})$ & $13.6(10.5-15.3)$ & $(8.1-9.7)$ & $\mathrm{U}$ & 0.143 \\
\hline WBC count $\left(\times 10^{9} / \mathrm{L}\right)$ & $10.7(7.7-15.5)$ & $(10.3-10.4)$ & $\mathrm{U}$ & 0.884 \\
\hline Platelet count $\left(\times 10^{9} / \mathrm{L}\right)$ & $197.3(137.2-250.2)$ & $(120.3-154.2)$ & $\mathrm{U}$ & 0.352 \\
\hline Basophil count $(\times 109 / \mathrm{L})$ & $0.3(0.3-0.5)$ & $(0.2-0.3)$ & $\mathrm{U}$ & 0.585 \\
\hline Eosinophil count $\left(\times 10^{9} / \mathrm{L}\right)$ & $0.2(0.1-0.6)$ & $(0.2-0.3)$ & $\mathrm{U}$ & 0.915 \\
\hline Neutrophil count $\left(\times 10^{9} / \mathrm{L}\right)$ & $78.0(54.4-86.2)$ & $(82.3-82.8)$ & $\mathrm{U}$ & 0.410 \\
\hline Lymphocyte count $\left(\times 10^{9} / \mathrm{L}\right)$ & $11.6(7.2-18.4)$ & $(11.1-11.7)$ & $\mathrm{U}$ & 0.994 \\
\hline Monocyte count $\left(\times 10^{9} / \mathrm{L}\right)$ & $8.5(4.5-14.0)$ & $(4.5-5.1)$ & $\mathrm{U}$ & 0.336 \\
\hline C-reactive protein $(\mathrm{mg} / \mathrm{l})$ & $49.0(15.7-96.0)$ & $(112.0-154.3)$ & $\mathrm{U}$ & $0.038^{*}$ \\
\hline D-dimer (ng/ml) & $100.0(20.0-221.0)$ & $(9.0-19.5)$ & $\mathrm{U}$ & 0.168 \\
\hline AST (U/L) & $57.0(25.0-120.0)$ & $(110.0-112.0)$ & $\mathrm{U}$ & 0.378 \\
\hline ALT $(U / L)$ & $51.2(32.0-120.0)$ & $(60.3-90.1)$ & $\mathrm{U}$ & 0.433 \\
\hline Bilirubin (mg/dl) & $0.7(0.6-0.8)$ & $(0.5-0.6)$ & $\mathrm{U}$ & 0.421 \\
\hline Albumin $(\mathrm{g} / \mathrm{dl})$ & $3.7(3.1-3.9)$ & $(3.2-3.3)$ & $\mathrm{U}$ & 0.436 \\
\hline Ferritin (ng/ml) & $120.0(50.0-300.0)$ & $(30.0-115.0)$ & $\mathrm{U}$ & 0.604 \\
\hline Fecal calprotectin $(\mathrm{mic} / \mathrm{g})$ & $40.0(20.0-62.5)$ & $(70.0-80.0)$ & $\mathrm{U}$ & 0.061 \\
\hline
\end{tabular}

${ }^{*} \mathrm{p}<0.05$

Table 3 Correlation between disease severity and clinical and biochemical characteristics in COVID-19 patients presenting with gastrointestinal and chest symptoms

\begin{tabular}{|c|c|c|c|c|}
\hline & Mild/Moderate $(n=17)$ & Severe/Critical $(n=42)$ & Test & p-value \\
\hline Male gender & $11(64.7 \%)$ & $22(52.4 \%)$ & \multirow[t]{2}{*}{0.746} & \multirow[t]{2}{*}{0.388} \\
\hline Female & $6(35.3 \%)$ & $20(47.6 \%)$ & & \\
\hline Age & $40.0(35.0-45.0)$ & $40.0(39.0-55.0)$ & $\mathrm{U}$ & 0.248 \\
\hline Hemoglobin $(\mathrm{g} / \mathrm{l})$ & $13.4(11.7-14.3)$ & $13.7(11.7-14.4)$ & $\mathrm{U}$ & 0.893 \\
\hline WBC count $\left(\times 10^{9} / \mathrm{L}\right)$ & $14.0(8.5-17.1)$ & $13.4(7.4-15.9)$ & $\mathrm{U}$ & 0.417 \\
\hline Platelet count $\left(\times 10^{9} / \mathrm{L}\right)$ & $154.0(124.6-223.5)$ & $140.2(118.1-205.3)$ & $\mathrm{U}$ & 0.332 \\
\hline Basophil count $\left(\times 10^{9} / \mathrm{L}\right)$ & $0.4(0.2-0.5)$ & $0.4(0.3-0.5)$ & $\mathrm{U}$ & 0.728 \\
\hline Eosinophil count $\left(\times 10^{9} / \mathrm{L}\right)$ & $0.2(0.1-0.5)$ & $0.2(0.1-0.4)$ & $\mathrm{u}$ & 0.864 \\
\hline Neutrophil count $\left(\times 10^{9} / \mathrm{L}\right)$ & $86.7(76.4-91.0)$ & $83.7(74.8-90.3)$ & $\mathrm{U}$ & 0.947 \\
\hline Lymphocyte count $\left(\times 10^{9} / L\right)$ & $7.2(5.5-17.6)$ & $10.0(6.0-16.7)$ & $\mathrm{U}$ & 0.487 \\
\hline Monocyte count $\left(\times 10^{9} / \mathrm{L}\right)$ & $5.2(3.9-7.4)$ & $7.2(4.1-12.9)$ & $\mathrm{u}$ & 0.119 \\
\hline C-reactive protein $(\mathrm{mg} / \mathrm{l})$ & $112.0(25.9-120.0)$ & $76.8(15.0-112.0)$ & $\mathrm{U}$ & 0.113 \\
\hline D-dimer (ng/ml) & $20.0(15.0-855.0)$ & $221.0(45.0-1121.0)$ & $\mathrm{U}$ & $0.031^{*}$ \\
\hline AST (units/L) & $44.3(24.7-100.4)$ & $77.1(28.9-142.9)$ & $\mathrm{U}$ & 0.200 \\
\hline ALT (units/L) & $60.0(31.0-142.5)$ & $109.6(36.6-143.2)$ & $\mathrm{U}$ & 0.389 \\
\hline Bilirubin (mg/dl) & $0.7(0.4-0.9)$ & $0.9(0.6-1.0)$ & $\mathrm{U}$ & 0.194 \\
\hline Albumin $(\mathrm{g} / \mathrm{dl})$ & $3.7(3.3-3.8)$ & $3.6(3.3-3.9)$ & $\mathrm{U}$ & 0.762 \\
\hline Ferritin $\mathrm{ng} / \mathrm{mL}$ & $120.0(70.0-300.0)$ & $190.0(50.0-325.0)$ & $\mathrm{U}$ & 0.847 \\
\hline Fecal calprotectin $(\mathrm{mic} / \mathrm{g})$ & $150.0(135.0-165.0)$ & $200.0(180.0-250.0)$ & $\mathrm{u}$ & $0.000^{*}$ \\
\hline
\end{tabular}

Values are expressed as median (IQR) or number (\%).

${ }^{*} \mathrm{p}<0.05$ 
Table 4 Correlation coefficient and p-value between disease severity and C-reactive protein in COVID-19 patients presenting with chest symptoms only

\begin{tabular}{|l|l|l|}
\hline & rs & $p$-value \\
\hline C-reactive protein (mg/l) & 0.169 & $0.037^{*}$ \\
\hline
\end{tabular}

${ }^{*} \mathrm{p}<0.05$

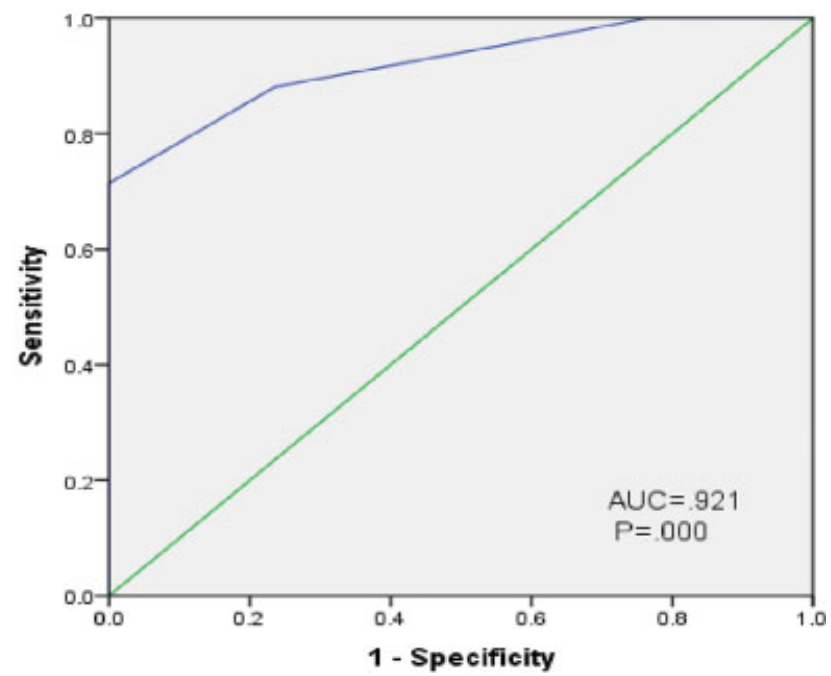

Fig. 2 ROC curve of fecal calprotectin between mild/moderate and severe/critical in COVID-19 patients group B (presenting with $\mathrm{Gl}$ and chest symptoms).

\section{Authors Contributions}

Maksoud H. A. A. analyzed the data and Hussien M. interpreted the patient data. Mohamed A and Sherief D. E. collected the data. Nossier N. A. and Mabrok A. contributed with the writing of the manuscript.

All authors read and approved the final manuscript

\section{Conflict of Interests}

The authors have no conflict of interests to declare.

\section{References}

1 Abd-Elsalam S, Esmail ES, Khalaf M, et al. Tanta Protocol for Management of COVID-19: Perspectives from a Developing Country. Endocr Metab Immune Disord Drug Targets 2020; •*;;. Doi: 10.2174/1871530320999201117142305

2 Elshaarawy O, Lashen SA, Makhlouf NA, et al. Barriers for resuming endoscopy service in the context of COVID-19 pandemic: A multicenter survey from Egypt. World J Gastroenterol 2020;26 (43):6880-6890

3 Hamming I, Timens W, Bulthuis ML, Lely AT, Navis G, van Goor H. Tissue distribution of ACE2 protein, the functional receptor for SARS coronavirus. A first step in understanding SARS pathogenesis. J Pathol 2004;203(02):631-637

4 Sarin SK, Choudhury A, Lau GK, et al; APASL COVID Task Force, APASL COVID Liver Injury Spectrum Study (APCOLIS Study-NCT
Table 5 Correlation coefficient and p-value between disease severity and D-dimer and fecal calprotectin in COVID-19 patients group B (presenting with gastrointestinal and chest symptoms)

\begin{tabular}{|l|l|l|}
\hline & rs & p-value \\
\hline D-dimer $(\mathrm{ng} / \mathrm{ml})$ & 0.284 & $0.029^{*}$ \\
\hline Fecal calprotectin $(\mathrm{mic} / \mathrm{g})$ & 0.672 & $0.000^{*}$ \\
\hline
\end{tabular}

${ }^{*} \mathrm{p}<0.05$

04345640) Pre-existing liver disease is associated with poor outcome in patients with SARS CoV2 infection; The APCOLIS Study (APASL COVID-19 Liver Injury Spectrum Study). Hepatol Int 2020;14(05):690-700

5 Marjot T, Moon AM, Cook JA, et al. Outcomes following SARSCoV-2 infection in patients with chronic liver disease: An international registry study. J Hepatol 2021;74(03):567-577

6 Hanafy AS, Abd-Elsalam S. Challenges in COVID-19 drug treatment in patients with advanced liver diseases: A hepatology perspective. World J Gastroenterol 2020;26(46):7272-7286

7 Bauer W, Diehl-Wiesenecker E, Ulke J, et al. Outcome prediction by serum calprotectin in patients with COVID-19 in the emergency department. J Infect 2021;82(04):84-123

8 World Health Organization. Clinical Management of Severe Acute Respiratory Infection (SARI) When COVID-19 Disease Is Suspected: Interim Guidance, 13 March 2020. World Health Organization; 2020

9 National Health Commission of the People's Republic of China. Notice on the novel coronavirus infection diagnosis and treatment plan (trial version seventh). In: National Health Commission of the People's Republic of China, editor. Beijing, 2020. Available From: http://www.nhc.gov.cn/wjw/gfxwjj/list_5.shtml

10 Huang C, Wang Y, Li X, et al. Clinical features of patients infected with 2019 novel coronavirus in Wuhan, China. Lancet 2020;395 (10223):497-506

11 Liu J, Li S, Liu J, et al. Longitudinal characteristics of lymphocyte responses and cytokine profiles in the peripheral blood of SARSCoV-2 infected patients. EBioMedicine 2020;55:102763. Doi: 10.1016/j.ebiom.2020.102763

12 Wan S, Yi Q Fan S, et al. Characteristics of lymphocyte subsets and cytokines in peripheral blood of 123 hospitalized patients with 2019 novel coronavirus pneumonia (NCP). . Accessed 24 Mar 2020 From:https://www.medrxiv.org/content/ 10.1101/2020.02.10.20021832v1(2020)

13 Hoffmann M, Kleine-Weber H, Schroeder S, et al. SArS-CoV-2 cell entry depends on ACe2 and tMPrSS2 and is blocked by a clinically proven protease inhibitor. Cell 2020;181(02):271-280.e8. Doi: 10.1016/j.cell.2020.02.052

14 Zhang H, Kang Z, Gong H, et al. Digestive system is a potential route of COVID-19: an analysis of single-cell coexpression pattern of key proteins in viral entry process. Gut 2020;69:1010-1018

15 Querol-Ribelles JM, Tenias JM, Grau E, et al. Plasma d-dimer levels correlate with outcomes in patients with community-acquired pneumonia. Chest 2004;126(04):1087-1092. Doi: 10.1378/ chest.126.4.1087

16 Chen W, Zheng KI, Liu S, Yan Z, Xu C, Qiao Z. Plasma CRP level is positively associated with the severity of COVID-19. Ann Clin Microbiol Antimicrob 2020;19(01):18. Doi: 10.1186/s12941020-00362-2 